\section{Cureus}

\title{
What a Trainee Surgeon Should Know About Refeeding Syndrome: A Literature Review
}

Muneeba Nasir ${ }^{1}$, Balakh S. Zaman MBBS(KE), B.Sc, FCPS, MRCS(London). MRCS(Glasg) ${ }^{1}$, Ahmad Kaleem ${ }^{1}$

1. Mayo Hospital, King Edward Medical University, Lahore, PAK

$\square$ Corresponding author: Muneeba Nasir, muneeba.nasir112@gmail.com Disclosures can be found in Additional Information at the end of the article

\section{Abstract}

Refeeding syndrome (RFS) is potentially fatal, yet there is limited understanding regarding its management among general surgeons due in part to a lack of universally accepted guidelines for RFS diagnosis. The aim of this review is to equip general surgery trainees with the essentials of RFS including a review of the National Institute for Health and Care Excellence (NICE) best practice guidelines for RFS. We used the keywords "refeeding", "syndrome", and "hypophosphatemia” to search PubMed, Embase, and Medline databases. We reviewed approximately 130 indexed papers for relevance. Having profound knowledge of nutritional needs in critically ill patients will help trainee surgeons prevent illnesses in the spectrum of RFS, and, over time, this would immensely contribute to reducing the morbidity and mortality associated with RFS.

Categories: General Surgery

Keywords: refeeding syndrome, trainee surgeon, review

\section{Introduction And Background}

The concept of refeeding syndrome (RFS) was first established in the Second World War. Prisoners of war previously held in the Far East developed neurological and cardiac abnormalities precipitated by the rapid institution of nourishment [1]. RFS, which is potentially fatal, is defined as "significant fluid and electrolyte abnormalities pertaining to metabolic disturbances following rapid oral, enteral or parenteral refeeding in chronically undernourished patients" [2]. The most profound biochemical abnormality is hypophosphatemia, while other biochemical abnormalities include a disturbance of sodium and fluid balance; a deficiency of thiamine; hypomagnesemia; hypokalemia; and changes in protein, fat, and carbohydrate metabolism [3].

Received $02 / 19 / 2018$
Review began 03/20/2018

Review ended 03/24/2018 Published 03/28/2018

\section{(c) Copyright 2018}

Nasir et al. This is an open access article distributed under the terms of the Creative Commons Attribution License CC-BY 3.0., which permits unrestricted use, distribution, and reproduction in any medium, provided the original author and source are credited.
The data relevant to the incidence of RFS are deficient mainly because there is no universal consensus on one single definition of RFS. In a thoroughly designed prospective study conducted on a heterogeneous group of intensive care patients, nearly $34 \%$ of them developed hypophosphatemia soon after the commencement of feeding [4]. In 2010, a study conducted by the National Confidential Enquiry Into Patient Outcomes and Death of the United Kingdom on 877 records of adult patients who received total parenteral nutrition showed that $14.7 \%$ of those at high-risk of RFS developed stigmata of RFS with hypophosphatemia being the most significant biochemical abnormality [5]. Recently, in 2013, a national audit of parenteral nutrition cases conducted in six hospitals in New Zealand revealed RFS documented in 17.6\% of the cases [6]. All these studies illustrate the need for a thorough understanding of RFS by 


\section{Cureus}

clinicians at all levels.

There is currently limited understanding of RFS and its management among general surgeons due in part to a lack of universally accepted, internationally recognized guidelines for the detection and diagnosis of RFS [7]. As a result, surgeons are often not aware of this problem, and many patients who are at high risk of developing RFS are not managed in specialist care. Another alarming hurdle is the morbidity and mortality associated with RFS are not well documented, with only Level 2 and Level 3 evidence available in the literature. The aim of this review is to equip general surgeon trainees with the essentials of RFS awareness including a review of the National Institute for Health and Care Excellence (NICE) guidelines for best practices for the early recognition of RFS, given that prophylaxis is the best way to reduce morbidity and mortality associated with this underdiagnosed and undertreated condition.

\section{Review}

We used the keywords "refeeding”, "syndrome”, and "hypophosphatemia” to search PubMed, Embase, and Medline databases for relevant articles. We cross-checked our findings with a personal reference list and books. We reviewed approximately 130 indexed papers for relevance. The quality of evidence in the published articles was ascertained in accordance with the 2009 Levels of Evidence from the Oxford Centre for Evidence-Based Medicine [8].

\section{Pathogenesis: How does RFS develop?}

It is essential to understand the pathophysiological events causing metabolic and hormonal disturbances that lead to RFS to have a clear understanding of the tools necessary for its prevention. The flowcharts in Figure 1 and Figure 2 give a thorough overview of RFS pathogenesis [9-13].

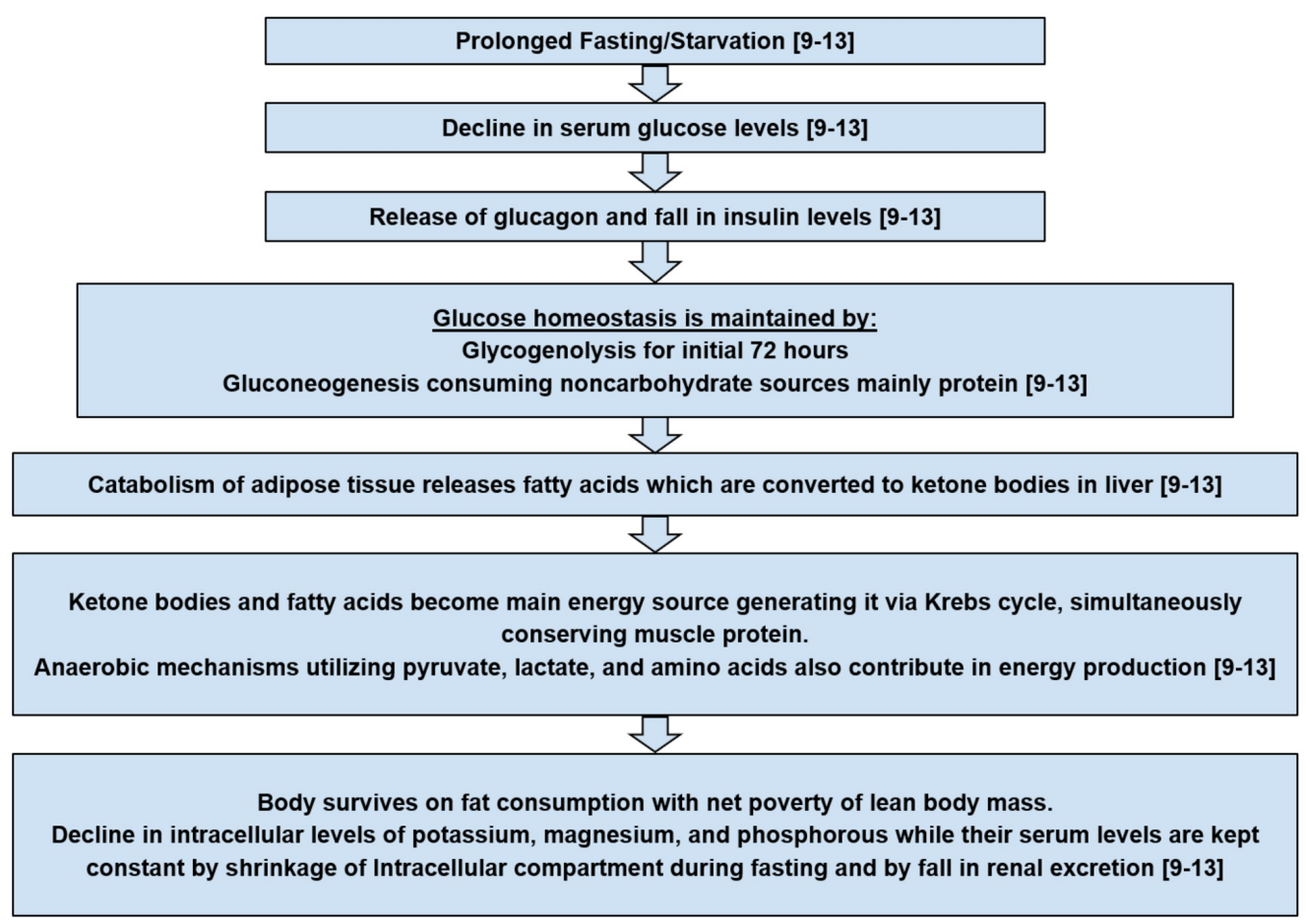

FIGURE 1: Pathogenesis of refeeding syndrome - flow chart 


\section{Cureus}

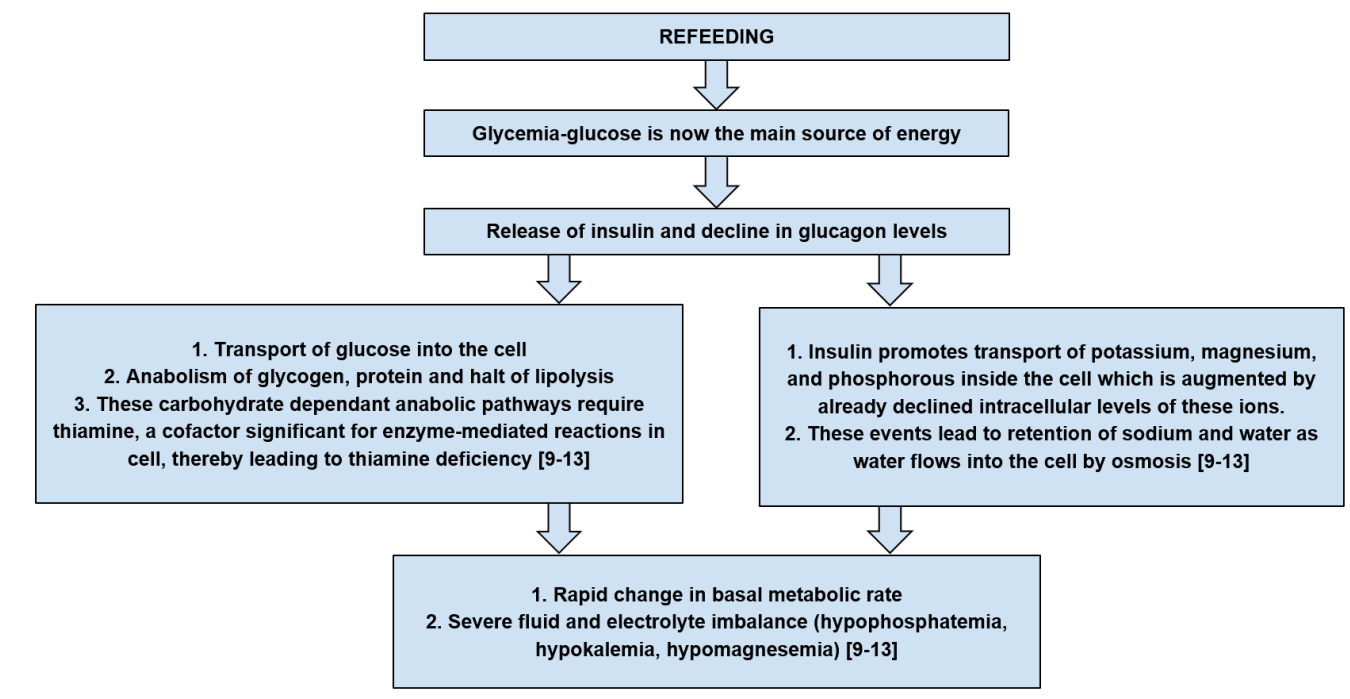

FIGURE 2: Metabolic and hormonal changes leading to refeeding syndrome

\section{Risk factors for developing RFS}

One of the pre requisites of developing RFS is chronic malnutrition. According to a study conducted by Hies et al. in 2005, nearly one-third to half of the patients admitted in the hospital are undernourished [14]. Table 1 provides the NICE guidelines for identifying patients at risk of acquiring RFS, which are a surgeon's best ally [15].

One Or More of The Following Symptoms

Body mass index $<16 \mathrm{~kg} / \mathrm{m} 2$

Unintentional weight loss $>15 \%$ in last six

months

Little or no nutritional intake for past 10 days

Low levels of potassium, phosphate or

magnesium prior to feeding
Or Two Or More of The Following Symptoms

Body mass index $<18.5 \mathrm{~kg} / \mathrm{m} 2$

Unintentional weight loss $>10 \%$ in last three to six months

Little or no nutritional intake for $>10$ days

A history of alcohol misuse or drugs including chemotherapy, insulin, diuretics or antacids

\section{TABLE 1: National Institute for Health and Care Excellence - guidelines for identifying patients at high risk of refeeding syndrome}

Other predominant risk factors of RFS are listed in Table 2, indicating the association between

RFS, comorbid conditions, and nutritional status [7,16-17]. 


\section{Cureus}

Patients with anorexia nervosa [7]

Patients with chronic alcoholism [15]

Oncology patients [16]

Chronic malnutrition (marasmus, under profound stress and undernourished > seven days, Malabsorptive disease) [15]

Postoperative patients [7]
Elderly patients (comorbid conditions) $[7,16]$

Uncontrolled diabetes mellitus [16]

Chronic pancreatitis [7]

Long-term use of antacids (as magnesium and aluminium bind phosphate) or diuretics (electrolyte imbalance) [15]

Acquired immune deficiency syndrome [7]

\section{TABLE 2: Patients at high risk of developing refeeding syndrome}

\section{Clinical manifestations of RFS}

The clinical spectra of RFS are reflective of disturbances in serum electrolyte and micronutrient levels affecting cell membrane potential and thereby impairing function in cardiac, nerve, and muscle cells. The severity of symptoms depends upon the extent of biochemical derangements and range from mild complaints of nausea and vomiting to life-threatening respiratory insufficiency and cardiac arrest. The clinical picture of RFS is highly unpredictable [4].

The clinical consequences of biochemical inadequacies in RFS are listed in Table 3 [18-19].

\begin{tabular}{|c|c|c|c|}
\hline Micronutrient & $\begin{array}{l}\text { Etiology of Micronutrient } \\
\text { Deficiency }\end{array}$ & $\begin{array}{l}\text { System Affected by } \\
\text { Micronutrient Deficiency }\end{array}$ & Clinical Consequences \\
\hline \multirow{6}{*}{$\begin{array}{l}\text { PHOSPHATE } \\
{[18-19]}\end{array}$} & $\begin{array}{l}\text { 1. Redistribution of cellular } \\
\text { phosphate }\end{array}$ & Cardiovascular & $\begin{array}{l}\text { Arrhythmia, cardiomyopathy, heart } \\
\text { failure, hypotension }\end{array}$ \\
\hline & 2. Loss from renal tubules & Neurological & $\begin{array}{l}\text { Convulsions, Altered sensorium, } \\
\text { tetany, delirium }\end{array}$ \\
\hline & 3. Deficient intake & Renal & $\begin{array}{l}\text { Metabolic acidosis, Acute Kidney } \\
\text { Injury }\end{array}$ \\
\hline & 4. Septic State & Hematological & $\begin{array}{l}\text { Hemolysis, decreased platelet } \\
\text { count, WBC dysfunction }\end{array}$ \\
\hline & 5. Liver pathology & Skeletal & $\begin{array}{l}\text { Myalgia, rhabdomyolysis, weakness } \\
\text { of the diaphragm }\end{array}$ \\
\hline & & Endocrine & $\begin{array}{l}\text { Insulin resistance, hyperglycemia, } \\
\text { osteomalacia }\end{array}$ \\
\hline \multirow{3}{*}{$\begin{array}{l}\text { THIAMINE } \\
\text { [18-19] }\end{array}$} & 1. Increased cellular usage & Neurological & $\begin{array}{l}\text { Wernicke-Korsakoff syndrome } \\
\text { (confusion, ataxia, psychosis) }\end{array}$ \\
\hline & & Cardiovascular & $\begin{array}{l}\text { Beriberi disease, congestive cardiac } \\
\text { failure }\end{array}$ \\
\hline & & Skeletal & Myalgias \\
\hline
\end{tabular}




\section{Cureus}

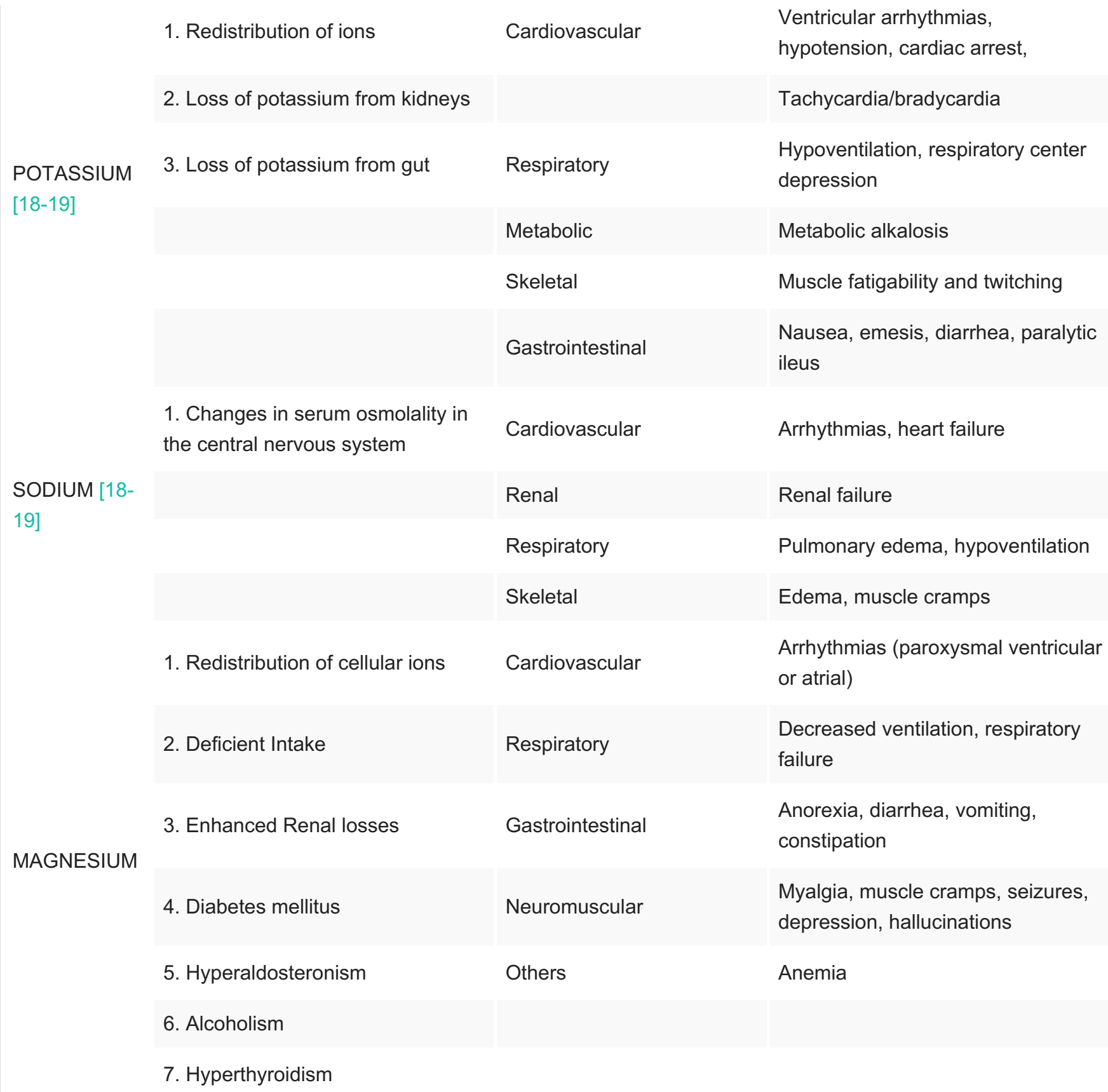

\section{TABLE 3: Clinical consequences of micronutrient abnormalities in refeeding}

syndrome

WBC: white blood cell.

\section{How could clinicians prevent RFS in hospitalized patients?}

The fundamental tool to successfully manage RFS is to prevent it by preferably adopting a multidisciplinary approach [20]. There are five basic approaches to prevent the development of RFS in hospitalized patients consisting of the early recognition of patients at high-risk of acquiring RFS; meticulous clinical and biochemical monitoring following the institution of refeeding in individuals in high-risk groups [18]; designing appropriate feeding regimens as seen in Table 4; screening patients at risk of developing RFS at the time of hospital admission; 


\section{Cureus}

and working with dieticians and nutritional team members to devise individualized refeeding strategies for each patient [21].

\section{Refeeding protocols in patients at high risk of developing RFS}

According to NICE, clinicians should commence refeeding at no greater than $50 \%$ of the energy needs in patients who have very little or no intake in the previous five days, and feeding rates should be tailored according to the patient's clinical response [15]. In all high-risk groups, nutrients need to be repleted slowly at $0.042 \mathrm{MJ} / \mathrm{kg} /$ day and are increased to fulfill or exceed needs in the following four to seven days [15]. In severely malnourished patients (i.e., those with a body mass index less than $14 \mathrm{~kg} / \mathrm{m} 2$ or a minimal intake for more than 14 days), it is advised to institute refeeding at $0.021 \mathrm{MJ} / \mathrm{kg} / \mathrm{day}$ with rigorous cardiac monitoring [15] Concurrent prophylactic supplementation of vitamins, restoration of fluid balance, and correction of biochemical disturbances are also recommended. Table 4 demonstrates refeeding regimens $[7,15,18,22]$.

\begin{tabular}{|c|c|c|}
\hline Macronutrient & $\begin{array}{l}\text { Day of } \\
\text { Refeeding }\end{array}$ & $\begin{array}{l}\text { Recommendation }[a=N I C E, b=\text { Stang } \\
\text { et al.. }{ }^{*}\end{array}$ \\
\hline ENERGY & 1st Day & (a) [NICE] Start with $10 \mathrm{kcal} / \mathrm{day}$ [15] \\
\hline & & $\begin{array}{l}\text { (b) [Stanga et al.]lf BMI is }<14 \mathrm{~kg} / \mathrm{m} 2 \\
\text { or starved for }>15 \text { days, initial intake } \\
=5 \mathrm{kcal} / \mathrm{kg} / \text { day [7] }\end{array}$ \\
\hline
\end{tabular}

2nd, 3rd, 4th Day

\begin{abstract}
(a) NICE Increase at $5 \mathrm{kcal} /$ day if minimal tolerance, stop/keep low feeding regimen [15]
\end{abstract}

(b) Stanga et al. $10 \mathrm{kcal} / \mathrm{day}$ and by the 4th day, give $15 \mathrm{kcal} / \mathrm{day}$ [7]

5th, 6th, 7th Day

(a) NICE Increase at $5 \mathrm{kcal} /$ day) if minimal tolerance, stop/keep low

\section{Prophylactic Micronutrient Supplementation in Tandem with the Institution of Feeding}

(a) Aim to keep "zero balance" by restricting fluids [18]

(b) Intravenous vitamin B complex and thiamine before starting feeding (IV $300 \mathrm{mg}$ when feeding instituted) [22]

(c) Sodium: $1 \mathrm{mmol} / \mathrm{kg} /$ day (restricted) [22]

(d) Phosphate up to $8 \mathrm{mmol} / \mathrm{kg} /$ day [22]

(e) Potassium: 1-3 mmol/kg/day [22]

(f) Magnesium: 0.3-0.4 mmol/kg/day [22]

(a) Identification and correction of biochemical abnormality if any (see Table 5)

(b) Continue intravenous thiamine until the 3rd day (100 mg/day as maintenance) [22]

(c) Rigorous clinical and biochemical monitoring $[18,22]$ feeding regimen [15]

(b) Stanga et al. 20-35 kcal/day [7] (a) Monitor renal and liver function tests

(b) Maintain "zero" fluid balance [22]

(c) Iron supplementation to be considered by day 7 [22]

(d) Continue clinical and biochemical 


\section{Cureus}

\begin{tabular}{|l|l|l|l|} 
& $\begin{array}{l}\text { 8th,9th,10th } \\
\text { Day }\end{array}$ & $\begin{array}{l}\text { (b) [Stanga et al.] 30-35 kcal/day or } \\
\text { feed to full need [7] }\end{array}$ \\
CARBOHYDRATES & Day 1 to 10 & $\begin{array}{l}\text { (a) NICE } 50 \% \text { to } 60 \% \text { of total energy } \\
\text { requirement [15] }\end{array}$ \\
FATS & Day 1 to 10 & $\begin{array}{l}\text { (a) NICE } 30 \% \text { to } 40 \% \text { of total energy } \\
\text { requirement [15] }\end{array}$ \\
PROTEIN & Day 1 to 10 & $\begin{array}{l}\text { (a) NICE } 15 \% \text { to } 20 \% \text { of total energy } \\
\text { requirement [15] }\end{array}$
\end{tabular}

\section{TABLE 4: Refeeding protocols in patients at high risk of developing refeeding syndrome}

*Strength of the recommendation (i.e., a and b) cannot be commented upon due to lack of randomised control trials conducted on RFS.

BMI: body mass index; IV: intravenous; NICE: National Institute for Health and Care Excellence.

\section{Monitoring in tandem with the institution of feeding in patients at high risk of developing RFS}

A clinician needs to keep a strict eye on clinical and biochemical parameters as soon as refeeding is started in hospitalized patients at significant risk of acquiring RFS. The meticulous clinical monitoring encompasses blood pressure and heart rate monitoring, strict control of refeeding rate, strict fluid intake/output recording, monitoring fluctuations in patient's weight, keeping an eye on neurological manifestations, and educating the patient. Biochemical monitoring consists of strictly recording daily serum electrolytes, arterial blood gas, and blood glucose levels, as well as monitoring electrocardiograms in critical cases and maintaining awareness of other energy resources $[18,23]$.

\section{Management of electrolyte and micronutrient inadequacies in RFS}

Given the potentially life-threatening outcomes of electrolyte abnormalities in RFS, it is essential to have a universally accepted regimen to correct such imbalances and identify inadequacies early, particularly in thiamine, phosphate, magnesium, potassium, and sodium levels to successfully manage RFS [17]. There is a lack of consensus on the best regimen to replete micronutrient and electrolyte deficiencies in RFS [18]. Following an extensive literature review, we have devised the protocols in Table 5 for the management of electrolyte imbalances in RFS [22,24-25].

Electrolyte Deficiency

HYPOPHOSPHATEMIA

$[22,25]$

(a) Mild (0.6-0.8 mmol/L)

\section{Correction Protocols}

1. $0.3-0.6 \mathrm{mmol} / \mathrm{kg} /$ day via oral route 


\section{Cureus}

Enhance intake via diet and add multivitamin supplement containing phosphate

(b) Moderate (0.3-0.6

$\mathrm{mmol} / \mathrm{L})$

(c) Severe $(<3 \mathrm{mmol} / \mathrm{L})$

HYPOMAGNESEMIA

$[22,25]$

(a) Mild $(0.7 \mathrm{mmol} / \mathrm{L})$

(b) Moderate (0.5-0.7 $\mathrm{mmol} / \mathrm{L}$ )

(c) Severe $(0.5 \mathrm{mmol} / \mathrm{L})$ HYPOKALEMIA [24]

(a) Mild (3-3.5 mmol/L)

(b) Moderate (2.5-3 $\mathrm{mmol} / \mathrm{L}$ )

(c) Severe (<3 mmol/L) HYPONATREMIA [24]

(a) Mild (130-135 mmol/L)

(b) Moderate (125-130 $\mathrm{mmol} / \mathrm{L}$ )

(c) Severe (<125 mmol/L)

THIAMINE [22]
1. $0.6 \mathrm{mmol} / \mathrm{kg}$ infused slowly intravenously over 6 hours or

2. 2-3.5 g/day via oral route in divided doses

1. Slow intravenous infusion at the rate of $1 \mathrm{mmol} / \mathrm{kg}$ over 12 hours

1. Oral supplementation with magnesium lactate or enhance dietary intake

1. Per oral intake of magnesium oxide/citrate (15 mmol/day) or

2. Intravenous slow infusion of $8-32 \mathrm{mmol} / \mathrm{kg}$ ( $\max , 0.5 \mathrm{mmol} / \mathrm{kg}$ ) with daily infusion of 8 mmol over 2 hours

1. Slow intravenous infusion of $32-64 \mathrm{mmol} / \mathrm{kg}$ ( $\mathrm{max}, 1 \mathrm{mmol} / \mathrm{kg}$ ) with $8 \mathrm{mmol}$ over 2 hours

1. Enhance dietary intake (40 $\mathrm{mmol} /$ day in 3 divided doses)

1. Oral: $20 \mathrm{mmol}$ in 3 divided doses every 2 hours or

2. Intravenous: Slow infusion of $10 \mathrm{mmol}$ over 1 hour. Recheck and infuse again if required

1. Slow intravenous infusion of $(40 \mathrm{mmol})$ over 2 hours

1. Restrict free fluid

1. Restrict free fluid

2. Intravenous infusion of half normal saline or saline with correction being done at (1-2 $\mathrm{mmol} /$ hour)

1. Replace at the rate of $2 \mathrm{mmol} /$ hour with $3 \%$ sodium chloride

1. Intravenous: $300 \mathrm{mg}$ at the institution of feeding

2. Maintenance dose: $100 \mathrm{mg}$

\section{TABLE 5: Management of electrolyte and micronutrient disturbances in refeeding} syndrome

\section{Conclusions}

All trainee surgeons taking care of vulnerable patients who might need nutritional supplementation should be able to ascertain the risk of RFS. So far, there has been no 
randomized controlled trials conducted on this potentially life-threatening syndrome and this is mainly attributable to the ethical restrictions. Instead, treatment is based on observational data. These facts emphasize the significance of having sound knowledge of the careful reinstitution of feeding in patients at high risk of developing RFS. Robust actions are needed to determine the incidence and arrive at a consensus on a set of guidelines for the management of RFS. Having profound knowledge of nutritional needs in critically ill, high-risk patients will help trainee surgeons prevent the onset of the illness spectrum of RFS. Prevention of RFS spectrum conditions would significantly contribute to reducing the morbidity and mortality of RFS. Following the review, we define RFS as "clinical spectra of fluid disturbances with either one or all of the biochemical abnormalities (i.e., hypophosphatemia, hypokalemia, hypomagnesemia and/or thiamine deficiency) resulting from metabolic changes precipitated by the rapid institution of enteral/parenteral feeding in chronically undernourished patients". However, robust studies should be conducted to formulate a universal definition of RFS, accurately ascertain the incidence of RFS, and devise optimal refeeding regimens via highquality, randomized controlled clinical trials.

\section{Additional Information Disclosures}

Conflicts of interest: In compliance with the ICMJE uniform disclosure form, all authors declare the following: Payment/services info: All authors have declared that no financial support was received from any organization for the submitted work. Financial relationships: All authors have declared that they have no financial relationships at present or within the previous three years with any organizations that might have an interest in the submitted work. Other relationships: All authors have declared that there are no other relationships or activities that could appear to have influenced the submitted work.

\section{References}

1. Schnitker MA, Mattman PE, Bliss TL: A clinical study of malnutrition in Japanese prisoners of war. Ann Intern Med. 1951, 35:69-96. 10.7326/0003-4819-35-1-69

2. Crook MA, Hally V, Panteli JV: The importance of the refeeding syndrome. Nutrition. 2001, 17:632-7. 10.1016/S0899-9007(01)00542-1

3. Hearing SD: Refeeding syndrome. BMJ. 2004, 328:908-9. 10.1136/bmj.328.7445.908

4. Marik PE, Bedigian MK: Refeeding hypophosphatemia in critically ill patients in an intensive care unit: a prospective study. Arch Surg. 1996, 131:1043-7. 10.1001/archsurg.1996.01430220037007

5. Stewart JA, Mason DG, Smith N, Protopapa K, Mason M: A Mixed Bag - An Enquiry into the Care of Hospital Patients Receiving Parenteral Nutrition: A Report by the National Confidential Enquiry into Patient Outcome and Death. London; 2010.

6. Rio A, Whelan K, Goff L, Reidlinger DP, Smeeton N: Occurrence of refeeding syndrome in adults started on artificial nutrition support: prospective cohort study. BMJ Open. 2013, 3:e002173. 10.1136/bmjopen-2012-002173

7. Stanga Z, Brunner A, Leuenberger M, Grimble RF: Nutrition in clinical practice-the refeeding syndrome: illustrative cases and guidelines for prevention and treatment. Eur J Clin Nutr. 2008, 62:687-94. 10.1038/sj.ejcn.1602854

8. Oxford Centre for Evidence-based Medicine - Levels of Evidence (March 2009) . 2009, Accessed: March 5, 2018: https://www.cebm.net/2009/06/oxford-centre-evidence-basedmedicine-levels-evidence-march-2009.

9. Berg JM, Tymoczko, JL, Stryer L: Biochemistry. W H Freeman, New York; 2002.

10. Ekberg K, Landau BR, Wajngot A, et al.: Contributions by kidney and liver to glucose production in the postabsorptive state and after $60 \mathrm{~h}$ of fasting. Diabetes. 1999, 48:292-298. 10.2337/diabetes.48.2.292

11. Kraft MD, Btaiche IF, Sacks GS: Review of the refeeding syndrome. Nutr Clin Pract. 2005, 20:625-33. 10.1177/0115426505020006625 
12. Hoffer LJ: Metabolic Consequences of Starvation. Modern Nutrition in Health and Disease. Shils M, Olson JA, Ross C (ed): Lippincott Williams and Wilkins, Baltimore; 2006. 730-748.

13. Klein CJ, Stanek GS, Wiles CE 3rd: Overfeeding macronutrients to critically ill adults: metabolic complications. J Am Diet Assoc. 1998, 98:795-806. 10.1016/S0002-8223(98)00179-5

14. Hise ME, Kattelmann K, Parkhurst M: Evidence-based clinical practice: dispelling the myths . Nutr Clin Pract. 2005, 20:294-302. 10.1177/0115426505020003294

15. National Institute for Health and Care Excellence. Nutrition support for adults: oral nutrition support, enteral tube feeding and parenteral nutrition. NICE. 2017, Accessed: February 27, 2018: https://www.nice.org.uk/guidance/cg32.

16. Mehanna H, Nankivell PC, Moledina J, Travis J: Refeeding syndrome-awareness, prevention and management. Head Neck Oncol. 2009, 1:4. 10.1186/1758-3284-1-4

17. Mehanna HM, Moledina J, Travis J: Refeeding syndrome: what it is, and how to prevent and treat it. BMJ. 2008, 336:1495-8. 10.1136/bmj.a301

18. Khan LU, Ahmed J, Khan S, Macfie J: Refeeding syndrome: a literature review . Gastroenterol Res Pract. 2011, 2011:410971. 10.1155/2011/410971

19. Stanga Z: Refeeding Syndrome. Basics in Clinical Nutrition. Sobotka L (ed): Galén, Czech Republic; 2011. 427-432.

20. Tresley J, Sheean PM: Refeeding syndrome: recognition is the key to prevention and management. J Am Diet Assoc. 2008, 108:2105-8. 10.1016/j.jada.2008.09.015

21. Tanswell I, Barrett D, Emm C, Lycett W, Charles C: Assessment by a multidisciplinary clinical nutrition team before percutaneous endoscopic gastrostomy placement reduces early postprocedure mortality. J Parenter Enteral Nutr. 2007, 31:205-11.

10.1177/0148607107031003205

22. Boateng AA, Sriram K, Meguid MM, Crook M: Refeeding syndrome: treatment considerations based on collective analysis of literature case reports. Nutrition. 2010, 26:156-167. 10.1016/j.nut.2009.11.017

23. Meier R, Stratton R: Basic concepts in nutrition: epidemiology of malnutrition. E Spen Eur E J Clin Nutr Metab. 2008, 3:167-70. 10.1016/j.eclnm.2008.04.002

24. Rhoda KM, Porter MJ, Quintini C: Fluid and electrolyte management: putting a plan in motion . J Parenter Enteral Nutr. 2011, 35:675-685. 10.1177/0148607111421913

25. Parli SE, Ruf KM, Magnuson B: Pathophysiology: treatment and prevention of fluid and electrolyte abnormalities during refeeding syndrome. J Infus Nurs. 2014, 37:197-202. 10.1097/NAN.0000000000000038 